\title{
$\alpha \beta$ T-cell receptor bias in disease and therapy (Review)
}

\author{
CHUN-YAN WANG ${ }^{1}$, PEI-FA YU ${ }^{1}$, XIAO-BING HE ${ }^{1}$, YONG-XIANG FANG ${ }^{1}$, \\ WEN-YU CHENG ${ }^{1}$ and ZHI-ZHONG JING ${ }^{1,2}$
}

\author{
${ }^{1}$ State Key Laboratory of Veterinary Etiological Biology, Key Laboratory of Veterinary Public Health \\ of Ministry of Agriculture, Lanzhou Veterinary Research Institute, Chinese Academy of Agricultural Sciences, \\ Lanzhou, Gansu 730046; ${ }^{2}$ Jiangsu Co-innovation Center for Prevention and Control of Important Animal \\ Infectious Diseases and Zoonoses, Yangzhou, Jiangshu 225009, P.R. China
}

Received January 31, 2016; Accepted March 21, 2016

DOI: $10.3892 /$ ijo.2016.3492

\begin{abstract}
The diversity and specificity of $\mathrm{T}$ cell receptors (TCR), the characteristics of T-cell surface marker, are central to the adaptive immunity. TCR variability is required for successful immunization coverage because this structural foundation is indispensable for the valid identification of short antigen peptides (derived from degraded antigens) that are presented by major histocompatibility molecules on the surfaces of antigen-presenting cells. Despite the vast T-cell repertoire, biased $\alpha \beta$ TCR has become a common theme in immunology. To date, numerous examples of TCR bias have been observed in various diseases. Immunotherapy strategies that are based on $\alpha \beta \mathrm{T}$ cell responses are also emerged as a prominent component of clinical treatment. In the present review, we briefly summarize the current knowledge regarding basic structural information and the molecular mechanisms underlying TCR diversity. Moreover, we outline the role of TCR repertoire bias in some diseases, and its application for therapeutic interventions, as these play significant roles in disease progression, even with patients with a good prognosis.
\end{abstract}

\section{Contents}

1. Introduction

2. TCR diversity and antigen recognition

3. TCR bias in disease

4. Antigen-specific TCR gene transduction

5. Conclusions

Correspondence to: Dr Zhi-Zhong Jing, State Key Laboratory of Veterinary Etiological Biology, Key Laboratory of Veterinary Public Health of Ministry of Agriculture, Lanzhou Veterinary Research Institute, Chinese Academy of Agricultural Sciences, Xujiaping 1, Lanzhou, Gansu 730046, P.R. China

E-mail: zhizhongj@163.com

Key words: T cell receptors, $\alpha \beta$ TCR, complementary determining region, TCR diversity, TCR bias, immunotherapy

\section{Introduction}

In mammals, thymus-derived T lymphocytes and bone-marrowderived B lymphocytes can generate wide repertoires of antigen receptors [T-cell receptors (TCR) and B-cell receptors (BCR), respectively]. These receptors enable the recognition of a myriad of antigens in mammals through primary participation in cellmediated immunity ( $\mathrm{T}$ cells) and humoral immunity (B cells). T cells are divided into the following two subsets: $\alpha \beta$ and $\gamma \delta$ $\mathrm{T}$ cells, according to the heterodimeric, disulphide bond-linked TCR structure (1). The domain structures of TCRs are strikingly similar to the structure of immunoglobulin Fab fragments, therefore, TCRs are also classified as members of the immunoglobulin superfamily. However, unlike immunoglobulins, which recognize intact protein antigens, the complementarity-determining region (CDR) loops of TCRs only recognize processed fragments of antigens that are presented by major histocompatibility complex (MHC) molecules on antigen-presenting cells (APCs), such as B cells, dendritic cells and macrophages $(2,3)$. These antigens that are recognized by TCR family members include peptides, glycoproteins, lipids and small molecule metabolites. Thus, the resulting TCR-peptide-MHC complex is of great importance in cellular immunity.

$\alpha \beta$ TCR are mainly expressed on the surfaces of $\alpha \beta \mathrm{T}$ and NKT cells, where they play a significant role in adaptive immune response by interacting with foreign antigens that are presented by MHC class I/II molecules on APCs. However, recent studies have described unconventional subsets of $\alpha \beta$ $\mathrm{T}$ cells bearing TCRs that can recognize ligand antigens that are presented by molecules of the MHC-like CD1 family or vitamin B based metabolites that are bound to MHC-related protein 1 (MR1). These subsets include: i) mucosal-associated invariant $\mathrm{T}$ cells which exhibited restricted diversity and are involved in antibacterial immunity (4,5); and ii) invariant natural killer T (NKT) cells and germ-line-encoded mycolylreactive (GEM) T cells, which recognize glycolipids with respect to CD1d and CD1b, respectively $(6,7)$. Other less wellcharacterized molecules are also known to recognize lipids that are presented by CD1a and CD1c molecules. In contrast, $\gamma \delta$ TCRs are mainly expressed on the surfaces of $\gamma \delta$ T cells, which comprise minority of the $\mathrm{T}$ cell pool but may represent more than half of the total $\mathrm{T}$ cells in tissues such as the gut and 
skin. In contrast to $\alpha \beta$ TCRs, $\gamma \delta$ TCRs recognize lipid-based antigens that are presented by $\mathrm{CD} 1$ molecules.

Regarding the functions of these two T-cell subsets, $\alpha \beta$ T cells play an important role in protective immunity against various antigens, whereas $\gamma \delta \mathrm{T}$ cells were previously considered to be a necessary component of innate immunity, the term 'T cell' generally refers to $\alpha \beta \mathrm{T}$ cells. However, in recent years, they have been considered to share important characteristics of both the innate and adaptive immune responses and have garnered increasing attention in the field of immunotherapy because of their prominent functions and direct or indirect participation in disease recovery (8).

Abundant TCR diversity is a prerequisite for broad immunological recognition, and antigen-specific TCRs are an important step in TCR gene transduction-based immunotherapy. Therefore, a clear understanding of TCR structure and diversity generation represents an elementary step in determining the best incorporation of $\alpha \beta$ TCRs in disease treatment strategies. Moreover, knowledge regarding TCR bias in different diseases could promote a good prognosis in patients treated via gene transfer. Accordingly, in the present review, we briefly introduce background information regarding TCR structure and diversity. In addition, we summarize recent data concerning TCR selection bias in some diseases, which might serve as a theoretical basis for clinical applications, and thus, further illuminate potential functions in disease treatment.

\section{TCR diversity and antigen recognition}

The highly variable TCR comprises a number of segments that are encoded by genes at discrete chromosomal locations: the $\alpha$ and $\gamma$ glycoprotein chains, which comprise $\mathrm{V}$ (variable), J (joining) and $\mathrm{C}$ (constant) regions and the $\beta$ and $\delta$ chains, which feature an additional $\mathrm{D}$ (diversity) region (9). The re-arrangement of $\mathrm{V}(\mathrm{D})$ and $\mathrm{J}$ through recombination signal sequences (RSS) and the formation of a functional antigen receptor via the activity of the lymphoid-specific protein recombination activating gene (RAG) 1 and RAG 2 exclusively occurs during thymocyte development (Fig. 1). This process involves the random re-arrangement of various $\mathrm{V}$ and $\mathrm{J}$ genes at the TCR- $\alpha$ locus and $\mathrm{V}, \mathrm{D}$ and $\mathrm{J}$ genes at the TCR- $\beta$ locus during T-cell development, additional diversity is produced by the random insertion or deletion of $>20$ non-germline nucleotides at region junctions (V-(N)-J, V-(N)-D and/or D-(N)-J; N represents nucleotide), thus, yielding a TCR recognition spectrum with an estimated theoretical diversity of $\sim 10^{18}$ in human (10) and $10^{15}$ in mouse (2) although most of those specificities will never be used during an individual's life, as peripheral repertoire in human are composed of $25 \times 10^{6}$ clonotypes (11) and $2 \times 10^{6}$ in mouse (1).

Three defined TCR hypervariable regions (CDR1, CDR2 and CDR3) combine to form the TCR antigen-binding site. Crystallographic analysis has revealed that CDR1 and CDR2 interact with a particular MHC molecule, whereas CDR3 interacts with the antigenic peptide bound to the MHC molecule $(12,13)$. Most variation in each chain lies within CDR3, which is responsible for the specific recognition of and interaction with peptide antigens that are presented by MHC molecules. As this region determines the antigen specificity of a $T$ cell, each CDR3 represents a single T-cell clone (14). CDR $1 \alpha$, CDR $1 \beta$,
$\mathrm{CDR} 2 \alpha$ and CDR2 $\beta$ are entirely encoded by the $\mathrm{V}$ region in germline DNA segments, whereas CDR3 loops are encoded by the $\mathrm{V}$ (D) $\mathrm{J}$ junction and the $\mathrm{N}$ additions and deletions during the recombination process; relative to CDR1 and CDR2 loops, CDR3 loops are significantly more diverse, and thus, mediate contact between TCR and the antigenic peptide-MHC complex. In addition, the D segment insertion occurs in CDR3 of the TRB/TRD locus, thus, yielding a broader TRB repertoire for antigen recognition compared with TRA and TRG. Whereas the CDR3 loop size distributions of the IgH and L chains and TCR $\gamma$ and $\delta$ chains are relatively broad and dissimilar, in contrast, the CDR 3 loop size distribution of the $\alpha$ and $\beta$ chain are narrow and closely matched, suggesting that a pairing of TCR $\alpha$ and $\beta$ chains with similar CDR3 loop sizes might be generally required to generate a functional $\alpha \beta$ TCR repertoire $(14,15)$. Furthermore, the greater diversity of the CDR $3 \beta$ loop (relative to the CDR $3 \alpha$ loop) might indicate that the TCR V $\beta$ chain is the main factor in determining TCR usage bias (16).

As each CDR3 sequence represents one $\mathrm{T}$ cell clone, the polyclonal or oligoclonal expansion of $\mathrm{T}$ cells can be determined through the detection of CDR3 spectratype by various methods such as PCR DNA blotting, PCR GeneScan sequence analysis, and high throughput TCR sequencing (TCR-seq) (17). The biased TCR AV and BV gene families are considered to be antigen-specific and can be used in immunotherapy.

\section{TCR bias in disease}

TCR diversity largely remains constant throughout the life span, except in infants and the elderly, because most specificity is generated in the thymus. However, under conditions of antigen exposure, the expansion of specific clonotypes is a common feature of immunity (Table I). Antigen-specific TCRs will demonstrate a preferential usage of particular TCR variable region gene segments, resulting in a TCR spectrum with a 'skewed', 'immunodominant', 'restricted' or 'limited' distribution, known as a 'biased' repertoire (16). TCR bias can be mainly classified into three types. Type 1 bias is characterised by selecting a single TCR gene family but with obvious diversity in the CDR3 sequences of different individual clones. Type 2 bias refers to the selection of the same amino acid motif in the CDR3 region of an antigen-specific TCR. Type 3 bias indicates a similar spectrum sequence, with differences resulting from different $\alpha$ and $\beta$ chain pairings. Several factors can influence TCR bias, including thymic selection, the initial immune response, persistent infection and selection of a 'private' versus 'public' TCR (16).

Tumor antigens. $\mathrm{T}$ lymphocytes play an effective role in antitumor immune responses (18). Various tumor-associated antigens (TAAs) that are used to discriminate between healthy and malignant tissue have been identified. In addition, antitumor cytotoxic T cells (CTLs), which exist within tumor-infiltrating lymphocyte (TIL) populations and the peripheral blood and generally comprise $\alpha \beta \mathrm{T}$ cells, have been detected in patients with cancer (19). The overexpression of a restricted TCR gene is a common characteristic of TILs. These proliferating monoclonal $\mathrm{T}$ cells, which play a basic role in tumor-specific cellular immune therapy, can be detected and separated using a gene re-arrangement analysis technology. 


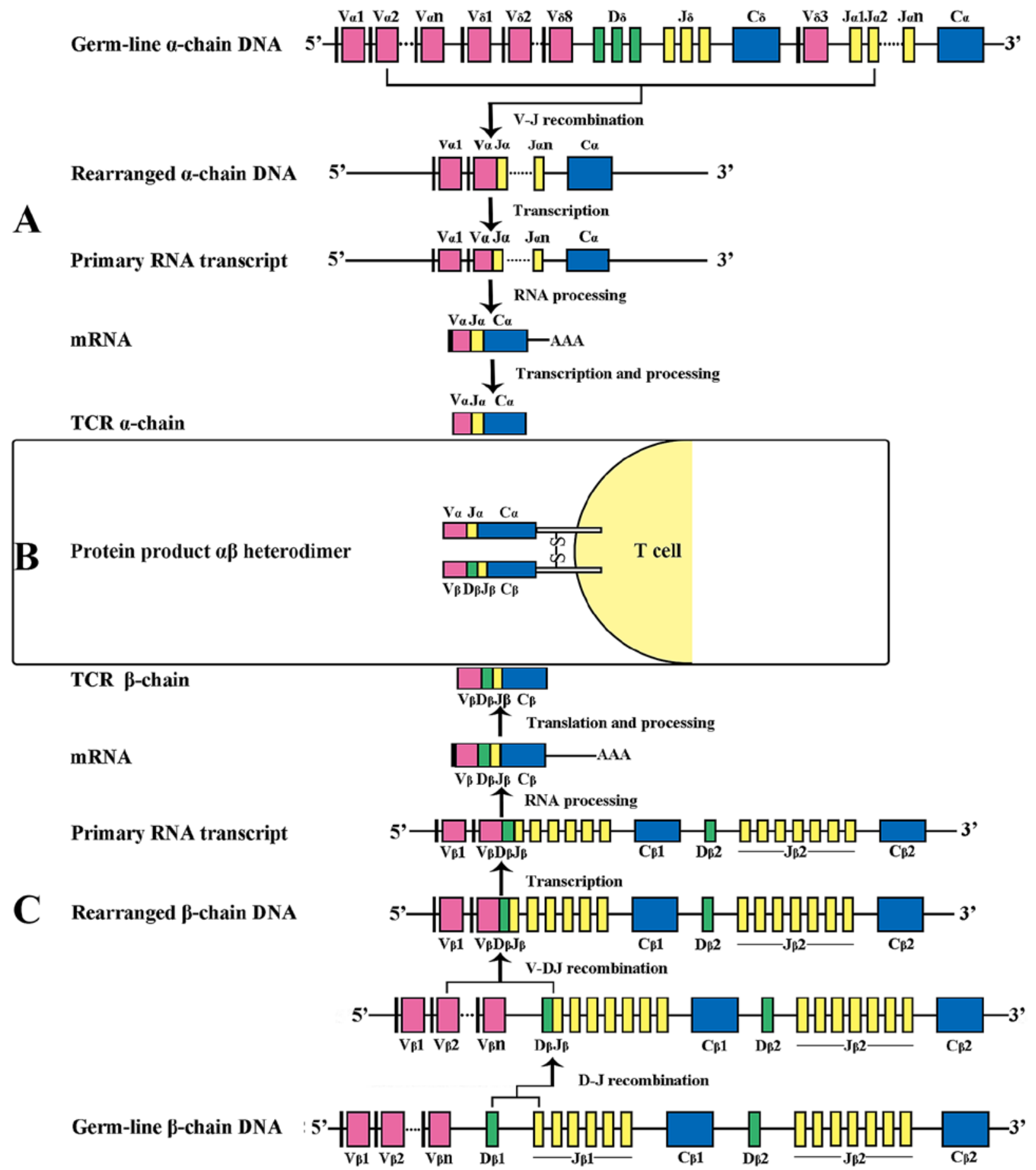

Figure 1. Examples of human TCR gene rearrangement, forming the functional gene encoding the $\alpha \beta$ heterodimer on the surface of T cells. (A) V-J recombination of the TCR- $\alpha$ chain DNA. The $\alpha$-chain DNA (in which the TCR- $\delta$ locus is also embedded), similar to the light-chain (L-chain) DNA of immunoglobulin, undergoes V-J recombination, brings together one of 46 TRAV segments and one of 51 TRAJ segments. The TCR- $\alpha$ transcript produced where V, J and C segments connect directly after the intron sequences are spliced out. (B) Heterodimer structure of $\alpha \beta-T C R$ on the surface of T lymphocytes. (C) V-D-J recombination of the TCR- $\beta$ chain DNA. The $\beta$-chain DNA is analogous to the heavy chain (H-chain) DNA of immunoglobulin, undergoes two-step recombination: first $D \beta$ to $J \beta$ and then $V \beta$ to $D \beta-J \beta$ rearrangement. The intervening sequences are then cut off, generating the TCR- $\beta$ chain transcript with $V, D, J$ and $C$ region adjacent. The leader sequence is removed from the nascent peptide chain. TCR, T cell receptor.

In some patients with melanoma, the number of T-cell clones of the same TRBV subfamily accounted for $>65 \%$ of TILs $(20,21)$, and TRBV14 was overexpressed in all patients who were human leukocyte antigen (HLA)-A2 positive but not in patients who were HLA-A2 negative $(22,23)$.

In 1994, Puisieux et al (24) observed that clonally proliferating TCR V $\alpha$ and TCR V $\beta$ tumor-specific CTLs could kill autologous tumor cells and subsequently transform into specific T-cell clones following isolation and in vitro cultivation. Monoclonal and oligoclonal expansions have been reported in patients with B-cell malignancies (19), and in B-cell chronic lymphocytic leukaemia (B-CLL), an oligoclonally expanded $\mathrm{BV} 19^{+} \mathrm{CD} 8^{+} \mathrm{T}$-cell subset has been demonstrated to specifically react with autologous leukemic B cells (25). TRBV overexpres- 
Table I. Examples of TCR bias in disease.

\begin{tabular}{|c|c|c|c|c|c|c|}
\hline \multirow[b]{2}{*}{ Diseases } & \multirow{2}{*}{$\begin{array}{c}\text { Antigen/ } \\
\text { antigen peptide }\end{array}$} & \multirow[b]{2}{*}{ MHC restriction } & \multirow[b]{2}{*}{ Source of $\mathrm{T}$ cell } & \multicolumn{2}{|c|}{ Priority of TCR genes } & \multirow[b]{2}{*}{ Ref. } \\
\hline & & & & TRAV & TRBV & \\
\hline \multicolumn{7}{|l|}{ Tumor } \\
\hline \multirow[t]{3}{*}{ B-CLL } & & & CD4 & & $2,3,5,6$ & (19) \\
\hline & & & CD8 & & 6,19 & (19) \\
\hline & & & $\mathrm{PB}$ & & 5 & (25) \\
\hline Melanoma & & & PB & & 6 & (21) \\
\hline \multirow[t]{2}{*}{ DLBCL } & & & $\mathrm{CD} 4$ & 6,23 & 3,13 & (28) \\
\hline & & & $\mathrm{PB}, \mathrm{TIL}$ & & 13,23 & (29) \\
\hline \multirow[t]{3}{*}{ CRC } & & & $\mathrm{CD} 4$ & & 12,16 , & $(31)$ \\
\hline & & & CD8 & & 19,21 & $(31)$ \\
\hline & & & $\mathrm{PB}, \mathrm{TIL}$ & & $12,16,19,21$ & (30) \\
\hline \multicolumn{7}{|l|}{ Infectious disease } \\
\hline \multirow[t]{4}{*}{ EBV } & EBNA3(339-347) & HLA-B*0801 & & $26-2$ & 7 & $(35,43)$ \\
\hline & EBNA1(407-417) & HLA-B*3508 & & 20,29 & 9 & (44) \\
\hline & & HLA-B*3501 & & & & \\
\hline & BZLF1(52-64) & HLA-B*3508 & & 1 & 10 & (45) \\
\hline Influenza virus & Matrix protein(58-66) & HLA-A2 & & & 19 & (48) \\
\hline \multirow[t]{3}{*}{ HIV } & Gag p17(77-85) & HLA-A2 & $\mathrm{PB}, \mathrm{CD} 8$ & & $5-6$ & (47) \\
\hline & Env & & & & $23-1$ & $(36)$ \\
\hline & p24 capsid & HLA-B*5703 & & 5 & 19 & (39) \\
\hline \multirow[t]{2}{*}{ SIV } & $\operatorname{Tat}(28-35)$ & Mamu-A*01 & $\mathrm{PB}, \mathrm{CD} 8$ & 22 & $6-5,14$ & (37) \\
\hline & $\operatorname{Gag}(181-189)$ & Mamu-A*01 & & & 13 & (37) \\
\hline Tuberculosis & & & & $11 / 3$ & 8 & (54) \\
\hline Malaria & & & & & $8.1,8.2$ & $(56)$ \\
\hline HCMV & pp65(495-503) & HLA-A2 & $\mathrm{PB}, \mathrm{CD} 8$ & 18 & $6-5,12-4$ & $(38)$ \\
\hline \multicolumn{7}{|l|}{$\begin{array}{l}\text { Autoimmune } \\
\text { disease }\end{array}$} \\
\hline \multirow[t]{4}{*}{ SLE } & & & PBMC & & $1,13-1,15,16$ & $(60,62)$ \\
\hline & & & Kidney & & 8,20 & $(58)$ \\
\hline & & & Skin & & 8,13 & (59) \\
\hline & & & Th lines & 8 & & (61) \\
\hline \multirow[t]{2}{*}{ T1D } & & & Pancreatic islets & & $1,7,11,17,22$ & (64) \\
\hline & & & Spleen, PB & & 22 & (63) \\
\hline
\end{tabular}

sion is more frequently observed in $\mathrm{CD}^{+} \mathrm{T}$ cells than in $\mathrm{CD}^{+} \mathrm{T}$ cells from patients with B-CLL (23), suggesting that leukemic B cells present MHC class II-restricted peptides to $\mathrm{CD}^{+} \mathrm{T}$ cells.

Specific $\mathrm{T}$ cells from some patients with myeloma can recognize tumor-derived idiotypic immunoglobulin, and patients with these idiotype-reactive $T$ cells are likely to have a better prognosis (26). No change in TRBV usage was detected between $\mathrm{T}$ cells that were cultured in a culture medium alone and with phytohemagglutinin stimulation, suggesting that the tumor-associated antigen-mediated selection of monoclonal and oligoclonal TCR families from stimulated T cells were indeed tumor specific (27). In addition, the clonal expansion of TRBV13 and TRBV23 in CD4 ${ }^{+} \mathrm{T}$ cells was identified in patients with diffuse large B-cell lymphoma (DLBCL) (28). Tan et al (29) conducted RT-PCR and GeneScan analysis of the
CDR3 repertoires of 29 TRAV and 24 TRBV gene families in PBMCs from patients with DLBCL and identified TRAV and TRBV gene bias.

Using a DNA melting curve method, Zhou et al (30) analysed the CDR3 spectratypes of peripheral blood and TIL from several patients with colorectal cancer (CRC). With respect to the response to $\mathrm{CRC}$ antigens, the prominent usage of TRBV16 was observed in peripheral blood T cells, and limited expression of the BV12, 19 and 21 gene families was detected; TILs from patients with CRC exhibited the same phenomena. Although no significant difference was observed between PBMCs and TILs, they found that the ratio of skewed TRBV gene families was higher among TILs than among PBMCs. Although dominant TCR repertoire usage varied among individuals, there is no lack of the same motif, 
which might imply that different patients can react to the same tumor antigen. Of greater interest is the dissimilarity in CDR3 gene sequences of PBMCs and TILs from the same patients (31). It remains unknown whether the same CDR3 motifs signify PBMCs and TILs that have proliferated in response to the same peptide antigen and whether proliferated PBMCs and/or TILs play a primary role in patients with CRC (30).

\section{Pathogenic infections}

Viral infection. Preferential selection of T-cell clones can contribute to the narrowing of an antigen-selected TCR repertoire (32), and such limited TCR repertoires have been observed in some $\mathrm{CD}^{+} \mathrm{T}$-cell subpopulations $(33,34)$. An increasing number of examples demonstrate the existence of TCR bias in antiviral immunity, and those restricted $\mathrm{V} \alpha$ and $\mathrm{V} \beta$ families expression and conserved CDR3 motifs are considered to be immune responders to definitive antigens. Such TCR bias has been observed in response to persistent infections with entities, such as the Epstein-Barr virus (EBV) (35), human immunodeficiency virus (HIV) (36), SIV (37), cytomegalovirus (CMV) (38) and influenza (39). However, this effect of selection is less apparent in the context of non-persistent antigens (16,34). Studies of EBV and CMV infection have demonstrated that TCR bias can result from the prior selection of T cells with high-affinity TCRs $(38,40)$; virus-specific memory $\mathrm{CD}^{+} \mathrm{T}$ cells have been detected in vitro (41).

EBV is a persistent entity that has infected $>90 \%$ of the population; in this context, biased TCR usage is mainly directed against several EBV antigens (42), and most restricted TCR family members exhibit sequence conservation according to specific antigen epitopes. EBNA1, EBNA3 and BZLF1 are three antigens for which structural data exist (43-45). Furthermore, in SIV-infected rhesus macaques, specific clonotypes are associated with protection, and a number of common clonotypes are closely associated with the viral load. Turner et al (16) considered three factors that might determine the constraint of a TCR repertoire during consistent infection: recognition of the peptide-MHC complex, antigen load (higher antigen load $=$ narrower TCR repertoire) and TCR diversity in the naïve pool. In patients with HIV, three so-called 'protective MHC alleles' have been identified: HLA-B*57, HLA-B*27 and HLA-B*58. These specific clonotypes are associated with protection and can predict disease prognosis $(46,47)$.

$\mathrm{CD}^{+} \mathrm{T}$ cells are the main population of immune cells that directly act against the pp65 protein (ALV/A2, 495-503) of HCLV, an immunodominant HLA-A2-restricted epitope. ALV/A2-specific $\mathrm{T}$ cells exhibited limited clonal diversity and restricted usage of the $\mathrm{V} \beta$ regions. The expansion of ALV/ A2-specific $\mathrm{T}$ cells were observed in response to HCMV activation and/or chronic inflammation, resulting in the selection of a single clonotype with similar public TCR features. High antigen avidity was also observed with ALV/A2-specific clonotypes, further proving that TCR avidity/affinity is the main concern with regard to persistent antigenic stimulation.

During the acute phase of SIV infection, $\mathrm{CD} 8^{+} \mathrm{T}$ cells respond to the TL8 (TTPESANL; Tat, residues 28-35) and CM9 (CTPYDINQM; Gag, residues 181-189) epitopes that are bound to codominant Mamu-A*01. Although TL8 and CM9 exhibit the same MHC class I restriction, they are associated with different patterns of conserved TRBV gene usage. Whereas TRBV13 usage was restricted in a majority of CM9-specific $\mathrm{CD}^{+} \mathrm{T}$ cells, TRBV14 usage was predominantly observed in TL8-specific CD8 ${ }^{+} \mathrm{T}$ cells. A highly conserved CDR3 motif (CASSXXRXSNQPQY) and preferential TRBJ1.5 usage were prevalent among TL8-specific clonotypes. In contrast, no such consensus was evident among CM9-specific CD8 ${ }^{+} \mathrm{T}$ cells. Furthermore, TL8-specific subtypes preferred a specific TRAV22 (37).

Conserved usage of the $\mathrm{V} \alpha$ and $\mathrm{V} \beta$ sequences were also observed in $\mathrm{T}$ cells that were specific for the influenza matrix peptide (58-66) $(47,48)$. In addition, the KF11 peptide (KAFSPEVIPMF) is among the immunodominant epitopes that are derived from the p24 capsid peptide of HIV $(39,42)$. A biased TCR repertoire displaying TRAV5 and TRBV19 and sharing common CDR $3 \alpha$ and CDR3 $\beta$ sequences was selected.

Tuberculosis. Tuberculosis (TB), which is caused by Mycobacterium tuberculosis, is a well-known common infectious disease (49). As M. tuberculosis is an intracellular bacterium, cell-mediated immunity acts as the driving force during bacterial elimination; in other words, CD4 ${ }^{+}$ and $\mathrm{CD}^{+} \mathrm{T}$ cells play important prophylactic roles against $\mathrm{TB}$ (50). The clonal expansion of $\mathrm{CD}^{+} \mathrm{T}$ cells in granuloma lesions and PBMCs has been observed $(51,52)$. In the infected lung, $\mathrm{CD}^{+} \mathrm{T}$ cells have been observed to secrete interferon gamma (IFN- $\gamma$ ) and tumor necrosis factor alpha (TNF- $\alpha$ ), both of which recruit and activate infected macrophages, thereby killing intracellular TB (53). Similarly, $\mathrm{CD}^{+} \mathrm{T}$ cells also produce IFN- $\gamma$ and TNF- $\alpha$ and mediate the cytolysis of infected macrophages; in addition, $\mathrm{CD}^{+} \mathrm{T}$ cells can kill M. tuberculosis within macrophages via granule-dependent mechanisms (54). As the $\mathrm{CD}^{+}$and $\mathrm{CD}^{+} \mathrm{T}$ cells of patients with TB exhibit decreased levels of functionality, promising therapeutic methods involve promoting an increase in T-cell functionality. Luo et al (54) screened TCR V $\alpha 11$ and V $\beta 8$ expression in $\mathrm{CD}^{+} \mathrm{T}$ cells and TCR V $\alpha 3$ and $\mathrm{V} \beta 8$ expression in $\mathrm{CD}^{+} \mathrm{T}$ cells because these are specific for a $38-\mathrm{kDa}$ antigen of M.tuberculosis; following transduction into primary CD4 ${ }^{+}$ and $\mathrm{CD}^{+} \mathrm{T}$ cells, these specific genes induced anti-M.tuberculosis activity. Furthermore, the CDR3 spectratypes of two $\mathrm{T}$ cell subpopulations were also analysed in 86 patients with different degrees of TB (55), and patients with TB were found to possess a restricted TCR repertoire when compared with healthy controls. A sequence analysis of CDR3 in clonally expanded $\mathrm{T}$ cells revealed a highly conserved amino acid motif in both the TCR $\alpha$ and $\beta$ chains. Severely infected patients exhibited less TCR diversity than did patients with mild disease, suggesting that TCR abundance negatively correlates with disease severity. Furthermore, CDR3 sequence conservation was found to be unrelated to the HLA phenotype; in other words, despite differences in individual HLA phenotypes, common TCR structural features may be observed in associated T cells.

Malaria. Among mice infected with cerebral malaria (CM), those lacking either the $\alpha \beta$ or $\gamma \delta$ T cells $\left(\mathrm{TCR} \alpha \beta^{-/-}\right.$or TCR $\left.\gamma \delta^{-/-}\right)$ differently manifested the disease. TCR $\gamma \delta^{-/-}$mice were susceptible to $\mathrm{CM}$, whereas $\mathrm{TCR} \alpha \beta^{-/-}$mice were resistant. Flow cytometric analysis of peripheral blood lymphocytes revealed 
that a subset of $\mathrm{CD}^{+} \mathrm{T}$ cells bearing the V $\beta 8.1$ and 2 segments was associated with disease severity (56).

Autoimmune disease. Autoimmune diseases are characterised by tissue damage resulting from an abnormal immune response toward autoantigens. During normal development, positive and negative thymic selection exclude $\mathrm{T}$ cells with a low or high affinity for self-MHC; under normal circumstances, the remaining TCRs with moderate self-affinity will not lead to autoimmune disease because of the inhibitory effects of regulatory $\mathrm{T}$ cells (Tregs) (57). However, under conditions of genetic vulnerability, many environmental factors can lead to the production of inflammatory cytokines and autoantibodies, which in turn can facilitate disease episodes. Abnormalities in humoral and cellular immunity are likely to be involved in autoimmune disease. Although autoantibodies, which are produced by the humoral immune system, target autoantigens, more recent reports demonstrate the contribution of abnormal T-cell proliferation to the secretion of these aberrant antibodies. As a result, studies concerning abnormal $\mathrm{T}$ cell activation address not only the cellular immune component of autoimmunity but also the humoral component.

In patients with SLE, limited expansion of $\mathrm{T}$ cells of the TCR $\beta$ gene family has been observed in the kidney (58), damaged areas of the skin (59) and peripheral blood (60-62). A conserved CDR3 amino acid motif (GGX) has also been detected in PBMCs from 20 patients with SLE. In human patients with type 1 diabetes (T1D), T cells that infiltrate the pancreatic islets mainly express TCRs of the BV gene family, with monoclonal expansion of $\mathrm{T}$ cells expressing $\mathrm{V} \beta 1, \mathrm{~V} \beta 7$, $\mathrm{V} \beta 11, \mathrm{~V} \beta 17$ and $\mathrm{V} \beta 22$. A monoclonal expansion of cells expressing V $\beta 22$ with a conserved CDR3 sequence was also observed in the peripheral blood, indicating the homing of circulating cells (63). Zhou et al (64) also analysed $\alpha \beta$ TCR distributions in the peripheral blood of patients with T1D, which may be relevant to the onset.

Furthermore, TCR plays a key role in T cell-mediated transplant rejection. Kim et al (65) analysed the TCR $\beta$ chain variable gene usage bias in the graft-infiltrating $\mathrm{CD} 8^{+}$ T lymphocytes in a human transplanted hand over 178 days, they found the TCR variable gene usage and size distribution revealed the oligoclonality expansion of some TCR gene families. These restricted TCR BV gene are likely to be associated with graft rejection. Aberrant TCR activity has been found to be associated with drug-linked hypersensitivity. Changes in TCR repertoire during treatment correspond with the patients' levels of morbidity (66), thus, a diverse TCR repertoire indicates a healthy condition or good disease outcome.

The tracking of antigen-specific TCRs related to tumors and various pathogenic infections will facilitate an understanding of disease progression. For example, in patients expressing HLA-A2, the CDR3 regions of T cells expressing V $\beta 17$ share the same unique sequence; in contrast, this sequence is difficult to detect in healthy individuals. Another example is TCR- $\beta$ oligoclonality with respect to autologous stem cell transplantation. Given the differences in TCR repertoire distribution between a healthy and diseased state, oligoclonality can be used as a marker of the degree of tumor cell elimination and the extent of immune reconstitution, and thus, may facilitate the evaluation of treatment efficiency (49). In patients with colorectal cancer, chemotherapy gradually increases the TCR diversity, suggesting favourable prognosis (66). Treating metastatic CRC with bevacizumab combined with modified irinotecan, fluorouracil and leucovorin (mIFL) results in a more normal TCR repertoire than does treatment with mIFL alone (67). All of these changes in repertoire prior to disease onset and after treatment may reflect a relationship between TCR repertoire normalization and relief from disease, and therefore, might indicate the potential diagnostic value of this parameter in a clinical setting (66).

\section{Antigen-specific TCR gene transduction}

In addition to the various disease treatments that have already been applied in the clinic, including tyrosine inhibitors and monoclonal antibody targeting of tumor-associated surface antigens, and potential suppression of antitumor immune responses, cytokines represent another form of immunotherapy that can modify the outcomes of innate or adaptive immunity, antitumor vaccines and adaptive gene therapies (68-78). However, the increased toxicity resulting from cytokine therapy can induce lymphocyte degeneration, reduce TCR repertoire diversity and increase susceptibility to opportunistic pathogens (79). To date, there are three kind of therapies: tumor-infiltrating lymphocytes (CILs), chimeric antigen receptors (CARs) and $\mathrm{T}$ cell receptor engineered $\mathrm{T}$ cells (80). This kind of transfer of lymphocytes to mediate an effector function is known as adaptive cell transfer (ACT). TILs have been developed with slow but continuing progress (80). Antigen-associated monoclonal TCR V $\alpha$ and $\mathrm{V} \beta$ gene families can be defined according to the length and sequence of the CDR3 region. In vitro experiments have confirmed that following efficient separation and amplification, these specific TCR genes can be incorporated into antitumor or antiviral disease therapy. However, it is difficult to gain a sufficient number of CTLs from the patients' $\mathrm{T}$ cell populations, thus, presenting a challenge to the application of this technique. In addition to the limited number of CTLs, immunosuppressive factors might help to downregulate effector T-cell functions. Accordingly, it would be meaningful to study the features and amplification methods that are associated with tumor-specific CTLs because these will play pivotal roles in antitumor adoptive immunotherapy.

All of these factors increase the attractiveness of $\mathrm{T}$ cell transduction-based immunotherapy, particularly with regard to long-term survival. The endowment of T cells with high-affinity antigen specificity via TCR transduction has highlighted the growing importance of this effective method with respect to the control and elimination of malignant cells and infectious agents.

Mainstream research has focused on the transduction of tumor or viral antigen-related TCR genes into normal T cells, including mandatory expression of the idiotypic TCR; as a result, the recognition patterns of endogenous TCRs are changed, leading to an increase in cytokine secretion and lethality after a large amplification, an immune response and the generation of the adequate numbers of specific CTLs during treatment. During this process, the TCR repertoires are dynamically monitored before, and for several cycles after therapy, by analysing the CDR3 length distributions 
within $\mathrm{CD}^{+}$and $\mathrm{CD}^{+} \mathrm{T}$ cell subsets. Recently, an in vitro expansion of tumor-specific CTLs was applied with clinical results. These TCR gene-engineered T cells were first used in the clinical treatment of melanoma. The introduction of a MART-1 antigen specific TCR gene into the peripheral blood lymphocytes of patients with melanoma may restore the capacity to resist positive tumor-surface antigens and might completely alter the disease prognosis.

Two methods can facilitate the transfer of exogenous genes into cells: viral vectors or chemical/physical methods (81). Viral vectors like gamma retrovirus and lentivirus enable efficient gene transfer with the least amount of damage; however, viral vectors are expensive, and the process represents a waste of time and resources. In addition, viral vectors cannot deliver large DNA fragments because of package capacity limitations. Furthermore, the potential for widespread viral contamination limits the application of this technique. In comparison, although physical methods, such as electroporation, can induce more cell death, these methods are faster, easier and safer methods of gene transfection, which explains their prominence. In recent years, a more advanced electroporation-based gene transfer method involving nucleofection has been introduced; this method transfers the gene of interest into the nuclei of non-dividing cells, with an high transfection efficiency.

In $1999, \mathrm{CD}^{+} \mathrm{T}$ cells that were genetically engineered to express the melanoma MART-1-restricted TCR $\alpha / \beta$ gene exhibited cytotoxicity against HLA-A2-restricted melanoma cells (82). In 2006, the first clinical trial was conducted (83); condition of 2 patients was completely restrained in 15 patients, win 18 months life time without this disease. Many examples of immunotherapy have been reported. The transduction of an HIV-specific TCR gene into patients with $\mathrm{HIV}-1^{+}$can enhance immunity. In addition, Tang et al (84) recently reviewed the mechanism by which the tumor microenvironment (TME) affects the efficiency of immunotherapy and how to best use TME as a contributor to immunotherapy. However, this kind of introduction of exogenous TCR gene may lead to mispairing of the endogenous TCR subunits with introduced TCR chain, which may alter the TCR specificity of antigen recognition, not only lead to the loss of antitumor, but also the formation of autoreactive T cells (85-87). Hu et al (91) have shown the humanized mouse (hu-mouse) model which transplantation of human fetal thymus tissue and $\mathrm{CD} 34^{+}$fetal liver cells into immunodeficient mice, leading to the development of human lymphohematopoietic cells and the formation of secondary lymphoid organs (88-90). They used this hu-mouse model to generate melanoma antigen (MART-1) specific human T cells for studies of human cancer immunotherapy. They found that MART-1 specific T cells can be generated after transduction of lentiviruses containing MART-1 specific TCR gene, implying that it was possible to produce large quantity of MART-1 specific $\mathrm{T}$ cells with antitumor activity.

The third and a powerful new immunotherapeutic approach intended to target TAAs comprises chimeric antigen receptors (CARs), which comprise an extracellular region - the antigenbinding domain of a monoclonal antibody (containing the variable domains of the light and heavy chains), a stem-like region, a transmembrane region and the intracellular signalling portion of a T-cell receptor, can combine the specificity and effectiveness of a monoclonal antibody with the cytotoxic effects and long-term persistence of CTLs (92), thus, it can make it possible to endow immune system with reactivity and add benefits which can be seen with cytotoxic chemotherapy or targeted therapy of the rapid onset of action. This method has been proven safe and effective for the induction of tumor remission in patients with neuroblastoma (93) and hematological malignancies (94). To date, the most successful CARs were those specific for CD19 on B cell malignances (92). Several research centres have confirmed the compelling efficacy of CARs against acute and chronic B-cell malignancies (95).

Compared with TCRs, there are several different parameters. First of all, these two format receptors target different antigens, TCRs react to natural ligands with MHC restriction, and it is necessary to enhance the affinity of the TCR with specific peptide-MHC in order to mediate the activities of $\mathrm{T}$ cells against the peptide-MHC antigen during the process of adoptive $\mathrm{T}$ cell therapy. In contrast, CARs are not MHC-dependent, and can function both in $\mathrm{CD}^{+}$and $\mathrm{CD}^{+} \mathrm{T}$ cells. Furthermore, CARs can induce activity even against low-density antigens. The CAR density, antigenbinding domain affinity still need to be optimized to match the antigen density of tumor and tissue (92). However, risk also exits because both on-target and off-target recognition of normal tissue occur in engineered $\mathrm{T}$ cells. For instance, in patients treated with carcino-embryonic antigen specific TCR modified $\mathrm{T}$ cells showed on-target toxicity, resulting in inflammatory colitis in normal colon (96). Apart from toxicity, both TCR and CARs will give rise to autoimmunity and inflammation from the infusion of ex vivo activated autologous lymphocytes. However, the incidence can be calculated to be less than one in 1,000 patients, which is lower than cytotoxic chemotherapy (97). A common challenge to all therapies, including antigen specific TCR gene based therapy, is to develop cost-effective, and efficient manufacturing and delivery capabilities (80).

\section{Conclusions}

Gene re-arrangement during the thymic development of $\mathrm{T}$ cells introduces sufficient TCR diversity to meet the varied requirements for antigen recognition. Over the last two decades, considerable research has demonstrated a close relationship between TCR diversity and immune responses against various antigens. Under natural conditions, the TCR repertoire is diverse and exhibits a Gaussian distribution, and the CDR3 of each gene family is represented by at least eight different lengths. As each CDR3 sequence represents a specific T-cell clone, CDR3 region spectratyping can reflect TCR clonality, and antigen-specific TCRs can be selected for immunotherapeutic use. A basic understanding of the T-cell receptor structure and recombination mechanisms can help us to understand the aetiology of TCR diversity and thus identify antigens.

An analysis of TCR bias in tumor, pathogenic infection, autoimmune disease and other disease settings is a basic prerequisite to a deep understanding of the immune mechanisms underlying antigen-specific responses and specific immunotherapy. Many studies have described how TCR abundance might be affected by certain infections, malignancies 
and immune dysfunctions. A broader specific peptide-MHC complex repertoire can help to reduce the emergence of a persistent viral infection. Three factors, thymic selection, initial immune response and persistent infection, are all known to influence specific TCR selection. In addition, some pathologies can induce the appearance of specific TCR clonotypes, which might be useful as immunological markers in clinical settings.

An understanding of T-cell responses against specific antigens is particularly important with respect to adaptive immunity. The immunotherapeutic role of $\alpha \beta \mathrm{T}$ cells has been strongly focused on their function in recovery from disease. In contrast, how would one capture the ideal TCR? It is necessary to monitor CDR3 spectratypes and conserved amino acid motifs. In addition to several above mentioned common methods, nascent high-throughput sequencing (TCR-seq) using next-generation sequencing also provides new insights to the sequence analysis of TCR repertoires under conditions of health and disease. The transduction of specific TCR genes with conserved CDR3 motifs into normal T cells can alter the original identification model and form antigen-specific $\mathrm{T}$ cells; this approach to disease treatment has yielded results that could further enhance the likelihood of survival. However, new strategies and methods still need be developed to enhance specific recognition between TCRs and antigens, with the aim of improving immunotherapeutic approaches to persistent infection and cancer.

\section{Acknowledgements}

The authors appreciate the support of the National Natural Science Funds (nos. 31372423 and 31302072) from the National Natural Science Foundation of China.

\section{References}

1. Casrouge A, Beaudoing E, Dalle S, Pannetier C, Kanellopoulos J and Kourilsky P: Size estimate of the alpha beta TCR repertoire of naive mouse splenocytes. J Immunol 164: 5782-5787, 2000.

2. Davis MM and Bjorkman PJ: T-cell antigen receptor genes and T-cell recognition. Nature 334: 395-402, 1988.

3. Jorgensen JL, Reay PA, Ehrich EW and Davis MM: Molecular components of T-cell recognition. Annu Rev Immunol 10: 835-873, 1992.

4. Treiner E, Duban L, Bahram S, Radosavljevic M, Wanner V, Tilloy F, Affaticati P, Gilfillan S and Lantz O: Selection of evolutionarily conserved mucosal-associated invariant $\mathrm{T}$ cells by MR1. Nature 422: 164-169, 2003.

5. Le Bourhis L, Martin E, Péguillet I, Guihot A, Froux N, Coré M, Lévy E, Dusseaux M, Meyssonnier V, Premel V, et al: Antimicrobial activity of mucosal-associated invariant $\mathrm{T}$ cells. Nat Immunol 11: 701-708, 2010.

6. Van Rhijn I, Kasmar A, de Jong A, Gras S, Bhati M, Doorenspleet ME, de Vries N, Godfrey DI, Altman JD, de Jager W, et al: A conserved human T cell population targets mycobacterial antigens presented by CD1b. Nat Immunol 14 706-713, 2013.

7. Beckman EM, Porcelli SA, Morita CT, Behar SM, Furlong ST and Brenner MB: Recognition of a lipid antigen by CD1-restricted $\alpha \beta^{+}$T cells. Nature 372: 691-694, 1994 .

8. Latha TS, Reddy MC, Durbaka PV, Rachamallu A, Pallu R and Lomada D: $\gamma \delta$ T Cell-mediated immune responses in disease and therapy. Front Immunol 5: 571, 2014.

9. Caccia N, Bruns GA, Kirsch IR, Hollis GF, Bertness V and Mak TW: T cell receptor alpha chain genes are located on chromosome 14 at 14q11-14q12 in humans. J Exp Med 161: 1255-1260, 1985.
10. Sewell AK: Why must T cells be cross-reactive? Nat Rev Immunol 12: 669-677, 2012.

11. Arstila TP, Casrouge A, Baron V, Even J, Kanellopoulos J and Kourilsky P: A direct estimate of the human alphabeta $\mathrm{T}$ cell receptor diversity. Science 286: 958-961, 1999.

12. Bentley GA, Boulot G, Karjalainen K and Mariuzza RA: Crystal structure of the beta chain of a T cell antigen receptor. Science 267: 1984-1987, 1995.

13. Fields BA, Ober B, Malchiodi EL, Lebedeva MI, Braden BC, Ysern X, Kim JK, Shao X, Ward ES and Mariuzza RA: Crystal structure of the $\mathrm{V} \alpha$ domain of a $\mathrm{T}$ cell antigen receptor. Science 270: 1821-1824, 1995.

14. Pannetier C, Cochet M, Darche S, Casrouge A, Zöller M and Kourilsky P: The sizes of the CDR3 hypervariable regions of the murine T-cell receptor beta chains vary as a function of the recombined germ-line segments. Proc Natl Acad Sci USA 90: 4319-4323, 1993.

15. Rock EP, Sibbald PR, Davis MM and Chien YH: CDR3 length in antigen-specific immune receptors. J Exp Med 179: 323-328, 1994.

16. Turner SJ, Doherty PC, McCluskey J and Rossjohn J: Structural determinants of T-cell receptor bias in immunity. Nat Rev Immunol 6: 883-894, 2006.

17. Woodsworth DJ, Castellarin M and Holt RA: Sequence analysis of T-cell repertoires in health and disease. Genome Med 5: 98, 2013.

18. Imai N, Ikeda H, Tawara I and Shiku H: Tumor progression inhibits the induction of multifunctionality in adoptively transferred tumor-specific CD8 ${ }^{+} \mathrm{T}$ cells. Eur J Immunol 39: 241-253, 2009.

19. Rezvany MR, Jeddi-Tehrani M, Osterborg A, Kimby E, Wigzell $\mathrm{H}$ and Mellstedt $\mathrm{H}$ : Oligoclonal TCRBV gene usage in B-cell chronic lymphocytic leukemia: Major perturbations are preferentially seen within the CD4 T-cell subset. Blood 94: 1063-1069, 1999.

20. Lake DF, Salgaller ML, van der Bruggen P, Bernstein RM and Marchalonis JJ: Construction and binding analysis of recombinant single-chain TCR derived from tumor-infiltrating lymphocytes and a cytotoxic T lymphocyte clone directed against MAGE-1. Int Immunol 11: 745-751, 1999.

21. Farina C, van der Bruggen P, Boël P, Parmiani G, Sensi M and Moretta L: Conserved TCR usage by HLA-Cw* 1601-restricted $\mathrm{T}$ cell clones recognizing melanoma antigens. Int Immunol 8: 1463-1466, 1996.

22. Boon T, Gajewski TF and Coulie PG: From defined human tumor antigens to effective immunization? Immunol Today 16: 334-336, 1995.

23. Salvi S, Segalla F, Rao S, Arienti F, Sartori M, Bratina G, Caronni E, Anichini A, Clemente C, Parmiani G, et al: Overexpression of the T-cell receptor beta-chain variable region TCRBV14 in HLA-A2-matched primary human melanomas. Cancer Res 55: 3374-3379, 1995.

24. Puisieux I, Even J, Pannetier C, Jotereau F, Favrot M and Kourilsky P: Oligoclonality of tumor-infiltrating lymphocytes from human melanomas. J Immunol 153: 2807-2818, 1994.

25. Farace F, Orlanducci F, Dietrich PY, Gaudin C, Angevin E, Courtier MH, Bayle C, Hercend T and Triebel F: T cell repertoire in patients with B chronic lymphocytic leukemia. Evidence for multiple in vivo T cell clonal expansions. J Immunol 153: 4281-4290, 1994.

26. Brown RD, Yuen E, Nelson M, Gibson J and Joshua D: The prognostic significance of $\mathrm{T}$ cell receptor beta gene rearrangements and idiotype-reactive T cells in multiple myeloma. Leukemia 11: 1312-1317, 1997.

27. Rezvany MR, Jeddi-Tehrani M, Wigzell H, Österborg A and Mellstedt H: Leukemia-associated monoclonal and oligoclonal TCR-BV use in patients with B-cell chronic lymphocytic leukemia. Blood 101: 1063-1070, 2003.

28. Li H, Ma X, Moskovits T, Inghirami G and Tsiagbe VK: Identification of oligoclonal CD4 T cells in diffuse large B cell lymphomas. Clin Immunol 107: 160-169, 2003.

29. Tan H, Ye J, Luo X, Chen S, Yin Q, Yang L and Li Y: Clonal expanded TRA and TRB subfamily T cells in peripheral blood from patients with diffuse large B-cell lymphoma. Hematology 15: 81-87, 2010.

30. Zhou J, Ma R, Luo R, Sun Y, He X, Sun W, Tang W and Yao X: Primary exploration of CDR3 spectratyping and molecular features of TCR $\beta$ chain in the peripheral blood and tissue of patients with colorectal carcinoma. Cancer Epidemiol 34: 733-740, 2010. 
31. Baier PK, Wimmenauer S, Hirsch T, von Specht BU, von Kleist S, Keller H and Farthmann EH: Analysis of the T cell receptor variability of tumor-infiltrating lymphocytes in colorectal carcinomas. Tumor Biol 19: 205-212, 1998.

32. McHeyzer-Williams LJ, Panus JF, Mikszta JA and McHeyzerWilliams MG: Evolution of antigen-specific T cell receptors in vivo: Preimmune and antigen-driven selection of preferred complementarity-determining region 3 (CDR3) motifs. J Exp Med 189: 1823-1838, 1999.

33. Busch DH and Pamer EG: T cell affinity maturation by selective expansion during infection. J Exp Med 189: 701-710, 1999.

34. Zhong W and Reinherz EL: In vivo selection of a TCR Vbeta repertoire directed against an immunodominant influenza virus CTL epitope. Int Immunol 16: 1549-1559, 2004.

35. Argaet VP, Schmidt CW, Burrows SR, Silins SL, Kurilla MG, Doolan DL, Suhrbier A, Moss DJ, Kieff E, Sculley TB, et al: Dominant selection of an invariant $\mathrm{T}$ cell antigen receptor in response to persistent infection by Epstein-Barr virus. J Exp Med 180: 2335-2340, 1994.

36. Pantaleo G, Demarest JF, Soudeyns H, Graziosi C, Denis F, Adelsberger JW, Borrow P, Saag MS, Shaw GM, Sekaly RP et al: Major expansion of $\mathrm{CD} 8^{+} \mathrm{T}$ cells with a predominant $\mathrm{V} \beta$ usage during the primary immune response to HIV. Nature 370 : 463-467, 1994.

37. Price DA, West SM, Betts MR, Ruff LE, Brenchley JM, Ambrozak DR, Edghill-Smith Y, Kuroda MJ, Bogdan D, Kunstman $\mathrm{K}$, et al: $\mathrm{T}$ cell receptor recognition motifs govern immune escape patterns in acute SIV infection. Immunity 21 : 793-803, 2004

38. Trautmann L, Rimbert M, Echasserieau K, Saulquin X, Neveu B, Dechanet J, Cerundolo V and Bonneville M: Selection of T cell clones expressing high-affinity public TCRs within Human cytomegalovirus-specific CD8 T cell responses. J Immunol 175 6123-6132, 2005

39. Gillespie GMA, Stewart-Jones G, Rengasamy J, Beattie T, Bwayo JJ, Plummer FA, Kaul R, McMichael AJ, Easterbrook P, Dong T, et al: Strong TCR conservation and altered T cell crossreactivity characterize a $\mathrm{B} * 57-$ restricted immune response in HIV-1 infection. J Immunol 177: 3893-3902, 2006

40. Price DA, Brenchley JM, Ruff LE, Betts MR, Hill BJ, Roederer M, Koup RA, Migueles SA, Gostick E, Wooldridge L, et al: Avidity for antigen shapes clonal dominance in $\mathrm{CD}^{+} \mathrm{T}$ cell populations specific for persistent DNA viruses. J Exp Med 202: $1349-1361,2005$.

41. Miconnet I, Marrau A, Farina A, Taffé P, Vigano S, Harari A and Pantaleo G: Large TCR diversity of virus-specific CD8 T cells provides the mechanistic basis for massive TCR renewal after antigen exposure. J Immunol 186: 7039-7049, 2011.

42. Gras S, Kjer-Nielsen L, Burrows SR, McCluskey J and Rossjohn J: T-cell receptor bias and immunity. Curr Opin Immunol 20: $119-125,2008$

43. Callan MF, Annels N, Steven N, Tan L, Wilson J, McMichael AJ and Rickinson AB: T cell selection during the evolution of $\mathrm{CD} 8^{+}$ T cell memory in vivo. Eur J Immunol 28: 4382-4390, 1998.

44. Miles JJ, Borg NA, Brennan RM, Tynan FE, Kjer-Nielsen L, Silins SL, Bell MJ, Burrows JM, McCluskey J, Rossjohn J, et al: TCR $\alpha$ genes direct MHC restriction in the potent human T cell response to a class I-bound viral epitope. J Immunol 177: 6804-6814, 2006.

45. Tynan FE, Burrows SR, Buckle AM, Clements CS, Borg NA, Miles JJ, Beddoe T, Whisstock JC, Wilce MC, Silins SL, et al: T cell receptor recognition of a 'super-bulged' major histocompatibility complex class I-bound peptide. Nat Immunol 6: 1114-1122, 2005.

46. Dolton G, Tungatt K, Lloyd A, Bianchi V, Theaker SM, Trimby A, Holland CJ, Donia M, Godkin AJ, Cole DK, et al: More tricks with tetramers: A practical guide to staining T cells with peptideMHC multimers. Immunology 146: 11-22, 2015.

47. Wilson JD, Ogg GS, Allen RL, Goulder PJ, Kelleher A, Sewell AK, O'Callaghan CA, Rowland-Jones SL, Callan MF and McMichael AJ: Oligoclonal expansions of CD8 ${ }^{+} \mathrm{T}$ cells in chronic HIV infection are antigen specific. J Exp Med 188: 785-790, 1998

48. Moss PA, Moots RJ, Rosenberg WM, Rowland-Jones SJ, Bodmer HC, McMichael AJ and Bell JI: Extensive conservation of alpha and beta chains of the human T-cell antigen receptor recognizing HLA-A2 and influenza A matrix peptide. Proc Natl Acad Sci USA 88: 8987-8990, 1991
49. Boehme CC, Nicol MP, Nabeta P, Michael JS, Gotuzzo E, Tahirli R, Gler MT, Blakemore R, Worodria W, Gray C, et al: Feasibility, diagnostic accuracy, and effectiveness of decentralised use of the Xpert MTB/RIF test for diagnosis of tuberculosis and multidrug resistance: A multicentre implementation study. Lancet 377: 1495-1505, 2011.

50. Geiger R, Duhen T, Lanzavecchia A and Sallusto F: Human naive and memory $\mathrm{CD}^{+} \mathrm{T}$ cell repertoires specific for naturally processed antigens analyzed using libraries of amplified $\mathrm{T}$ cells. J Exp Med 206: 1525-1534, 2009.

51. Tully G, Kortsik C, Höhn H, Zehbe I, Hitzler WE, Neukirch C, Freitag K, Kayser K and Maeurer MJ: Highly focused T cell responses in latent human pulmonary Mycobacterium tuberculosis infection. J Immunol 174: 2174-2184, 2005.

52. Jacobsen M, Detjen AK, Mueller H, Gutschmidt A, Leitner S, Wahn U, Magdorf K and Kaufmann SHE: Clonal expansion of $\mathrm{CD}^{+}$effector T cells in childhood tuberculosis. J Immunol 179: 1331-1339, 2007

53. Flynn JL and Chan J: Immunology of tuberculosis. Annu Rev Immunol 19: 93-129, 2001.

54. Luo W, Zhang XB, Huang YT, Hao PP, Jiang ZM, Wen Q, Zhou MQ, Jin Q and Ma L: Development of genetically engineered $\mathrm{CD}^{+}$and $\mathrm{CD}^{+} \mathrm{T}$ cells expressing TCRs specific for a M. tuberculosis 38-kDa antigen. J Mol Med Berl 89: 903-913, 2011.

55. Luo W, Su J, Zhang XB, Yang Z, Zhou MQ, Jiang ZM, Hao PP, Liu SD, Wen $\mathrm{Q}$, Jin $\mathrm{Q}$, et al: Limited $\mathrm{T}$ cell receptor repertoire diversity in tuberculosis patients correlates with clinical severity. PLoS One 7: e48117, 2012.

56. Boubou MI, Collette A, Voegtlé D, Mazier D, Cazenave PA and Pied S: T cell response in malaria pathogenesis: Selective increase in T cells carrying the TCR V $\beta 8$ during experimental cerebral malaria. Int Immunol 11: 1553-1562, 1999.

57. Li Y (ed): Research and application of T-cell receptor. People's Medical Publishing House, Beijing, 132, 2009 (in Chinese).

58. Murata H, Matsumura R, Koyama A, Sugiyama T, Sueishi M, Shibuya K, Tsutsumi A and Sumida T: T cell receptor repertoire of T cells in the kidneys of patients with lupus nephritis. Arthritis Rheum 46: 2141-2147, 2002.

59. Furukawa F, Tokura Y, Matsushita K, Iwasaki-Inuzuka K, Onagi-Suzuki K, Yagi H, Wakita $\mathrm{H}$ and Takigawa M: Selective expansions of $\mathrm{T}$ cells expressing $\mathrm{V} \beta 8$ and $\mathrm{V} \beta 13$ in skin lesions of patients with chronic cutaneous lupus erythematosus. J Dermatol 23: 670-676, 1996

60. Mato T, Masuko K, Misaki Y, Hirose N, Ito K, Takemoto Y, Izawa $\mathrm{K}$, Yamamori S, Kato T, Nishioka K, et al: Correlation of clonal $\mathrm{T}$ cell expansion with disease activity in systemic lupus erythematosus. Int Immunol 9: 547-554, 1997.

61. Desai-Mehta A, Mao C, Rajagopalan S, Robinson T and Datta SK: Structure and specificity of T cell receptors expressed by potentially pathogenic anti-DNA autoantibody-inducing T cells in human lupus. J Clin Invest 95: 531-541, 1995.

62. Luo W, Ma L, Wen Q, Wang N, Zhou MQ and Wang XN: Analysis of the interindividual conservation of $\mathrm{T}$ cell receptor $\alpha$ - and $\beta$-chain variable regions gene in the peripheral blood of patients with systemic lupus erythematosus. Clin Exp Immunol 154: 316-324, 2008.

63. Codina-Busqueta E, Scholz E, Muñoz-Torres PM, Roura-Mir C, Costa M, Xufré C, Planas R, Vives-Pi M, Jaraquemada D and Martí M: TCR bias of in vivo expanded T cells in pancreatic islets and spleen at the onset in human type 1 diabetes. J Immunol 186: 3787-3797, 2011.

64. Zhou J, Kong C, Jia Y, Wang L, Jin C and Wang X: The skewness of alpha beta $\mathrm{T}$ cell receptors in peripheral blood of the patients with type 1 diabetes. Exp Clin Endocrinol Diabetes 124: 1-4, 2016.

65. Kim JY, Balamurugan A, Azari K, Hofmann C, Ng HL, Reed EF, McDiarmid S and Yang OO: Clonal CD8 ${ }^{+} \mathrm{T}$ cell persistence and variable gene usage bias in a human transplanted hand. PLoS One 10: e0136235,2015

66. Luo W, Liao WJ, Huang YT, Shi M, Zhang Y, Wen Q, Zhou MQ and Ma L: Normalization of T cell receptor repertoire diversity in patients with advanced colorectal cancer who responded to chemotherapy. Cancer Sci 102: 706-712, 2011.

67. Luo W, Liao WJ, Ma L, Huang YT, Shi M, Wen Q and Wang XN: Dynamic monitoring the TCR CDR3 spectratypes in patients with metastatic CRC treated with a combination of bevacizumab irinotecan, fluorouracil, and leucovorin. Cancer Immunol Immunother 59: 247-256, 2010. 
68. Yu AL, Gilman AL, Ozkaynak MF, London WB, Kreissman SG, Chen HX, Smith M, Anderson B, Villablanca JG, Matthay KK, et al; Children's Oncology Group: Anti-GD2 antibody with GM-CSF, interleukin-2, and isotretinoin for neuroblastoma. N Engl J Med 363: 1324-1334, 2010.

69. Hank JA, Robinson RR, Surfus J, Mueller BM, Reisfeld RA, Cheung NK and Sondel PM: Augmentation of antibody dependent cell mediated cytotoxicity following in vivo therapy with recombinant interleukin 2. Cancer Res 50: 5234-5239, 1990.

70. Brahmer JR, Tykodi SS, Chow LQ, Hwu WJ, Topalian SL, Hwu P, Drake CG, Camacho LH, Kauh J, Odunsi K, et al: Safety and activity of anti-PD-L1 antibody in patients with advanced cancer. N Engl J Med 366: 2455-2465, 2012.

71. Topalian SL, Hodi FS, Brahmer JR, Gettinger SN, Smith DC, McDermott DF, Powderly JD, Carvajal RD, Sosman JA, Atkins MB, et al: Safety, activity, and immune correlates of anti-PD-1 antibody in cancer. N Engl J Med 366: 2443-2454, 2012.

72. Wolchok JD, Kluger H, Callahan MK, Postow MA, Rizvi NA, Lesokhin AM, Segal NH, Ariyan CE, Gordon RA, Reed K, et al: Nivolumab plus ipilimumab in advanced melanoma. N Engl J Med 369: 122-133, 2013.

73. Bowman L, Grossmann M, Rill D, Brown M, Zhong WY, Alexander B, Leimig T, Coustan-Smith E, Campana D, Jenkins J, et al: IL-2 adenovector-transduced autologous tumor cells induce antitumor immune responses in patients with neuroblastoma. Blood 92: 1941-1949, 1998.

74. Brenner MK, Heslop H, Krance R, Horowitz M, Strother D, Nuchtern J, Grilley B, Martingano E and Cooper K: Phase I study of chemokine and cytokine gene-modified autologous neuroblastoma cells for treatment of relapsed/refractory neuroblastoma using an adenoviral vector. Hum Gene Ther 11: 1477-1488, 2000

75. Pule MA, Savoldo B, Myers GD, Rossig C, Russell HV, Dotti G, Huls MH, Liu E, Gee AP, Mei Z, et al: Virus-specific T cells engineered to coexpress tumor-specific receptors: Persistence and antitumor activity in individuals with neuroblastoma. Nat Med 14: 1264-1270, 2008.

76. Louis CU, Savoldo B, Dotti G, Pule M, Yvon E, Myers GD, Rossig C, Russell HV, Diouf O, Liu E, et al: Antitumor activity and long-term fate of chimeric antigen receptor-positive $\mathrm{T}$ cells in patients with neuroblastoma. Blood 118: 6050-6056, 2011.

77. Park JR, Digiusto DL, Slovak M, Wright C, Naranjo A, Wagner J, Meechoovet HB, Bautista C, Chang WC, Ostberg JR, et al: Adoptive transfer of chimeric antigen receptor re-directed cytolytic T lymphocyte clones in patients with neuroblastoma. Mol Ther 15: 825-833, 2007.

78. Cheung NKV, Cheung IY, Kushner BH, Ostrovnaya I, Chamberlain E, Kramer K and Modak S: Murine anti-GD2 monoclonal antibody $3 \mathrm{~F} 8$ combined with granulocyte-macrophage colony-stimulating factor and 13-cis-retinoic acid in high-risk patients with stage 4 neuroblastoma in first remission. J Clin Oncol 30: 3264-3270, 2012.

79. Mackall CL, Fleisher TA, Brown MR, Magrath IT, Shad AT, Horowitz ME, Wexler LH, Adde MA, McClure LL and Gress RE: Lymphocyte depletion during treatment with intensive chemotherapy for cancer. Blood 84: 2221-2228, 1994.

80. June CH, Riddell SR and Schumacher TN: Adoptive cellular therapy: A race to the finish line. Sci Transl Med 7: 280ps7, 2015.

81. Zhang M, Ma Z, Selliah N, Weiss G, Genin A, Finkel TH and Cron RQ: The impact of Nucleofection ${ }^{\circledR}$ on the activation state of primary human CD4 T cells. J Immunol Methods 408: 123-131, 2014.
82. Clay TM, Custer MC, Sachs J, Hwu P, Rosenberg SA and Nishimura MI: Efficient transfer of a tumor antigen-reactive TCR to human peripheral blood lymphocytes confers anti-tumor reactivity. J Immunol 163: 507-513, 1999.

83. Duval L, Schmidt H, Kaltoft K, Fode K, Jensen JJ, Sorensen SM, Nishimura MI and von der Maase H: Adoptive transfer of allogeneic cytotoxic T lymphocytes equipped with a HLA-A2 restricted MART-1 T-cell receptor: a phase I trial in metastatic melanoma. Clin Cancer Res 12: 1229-1236, 2006.

84. Tang H, Qiao J and Fu YX: Immunotherapy and tumor microenvironment. Cancer Lett 370: 85-90, 2016.

85. Cohen CJ, Zhao Y, Zheng Z, Rosenberg SA and Morgan RA: Enhanced antitumor activity of murine-human hybrid T-cell receptor (TCR) in human lymphocytes is associated with improved pairing and TCR/CD3 stability. Cancer Res 66: 8878-8886, 2006.

86. Kuball J, Dossett ML, Wolfl M, Ho WY, Voss RH, Fowler C and Greenberg PD: Facilitating matched pairing and expression of TCR chains introduced into human T cells. Blood 109: 2331-2338, 2007.

87. Bendle GM, Linnemann C, Hooijkaas AI, Bies L, de Witte MA, Jorritsma A, Kaiser ADM, Pouw N, Debets R, Kieback E, et al: Lethal graft-versus-host disease in mouse models of $\mathrm{T}$ cell receptor gene therapy. Nat Med 16: 565-570, 1p, 570, 2010.

88. Lan P, Wang L, Diouf B, Eguchi H, Su H, Bronson R, Sachs DH, Sykes M and Yang YG: Induction of human T-cell tolerance to porcine xenoantigens through mixed hematopoietic chimerism. Blood 103: 3964-3969, 2004.

89. Lan P, Tonomura N, Shimizu A, Wang S and Yang YG: Reconstitution of a functional human immune system in immunodeficient mice through combined human fetal thymus/liver and CD $34^{+}$cell transplantation. Blood 108: 487-492, 2006.

90. Tonomura N, Habiro K, Shimizu A, Sykes M and Yang YG: Antigen-specific human T-cell responses and T cell-dependent production of human antibodies in a humanized mouse model. Blood 111: 4293-4296, 2008

91. Hu Z, Xia J, Fan W, Wargo J and Yang YG: Human melanoma immunotherapy using tumor antigen-specific $\mathrm{T}$ cells generated in humanized mice. Oncotarget: Jan 27, 2016 (Epub ahead of print).

92. Harris DT, Kranz DM and Adoptive T: Cell therapies: A comparison of $\mathrm{T}$ cell receptors and chimeric antigen receptors. Trends Pharmacol Sci 37: 220-230, 2015.

93. Heczey A and Louis CU: Advances in chimeric antigen receptor immunotherapy for neuroblastoma. Discov Med 16: 287-294, 2013.

94. Maus MV, Grupp SA, Porter DL and June CH: Antibody-modified T cells: CARs take the front seat for hematologic malignancies. Blood 123: 2625-2635, 2014.

95. Alrifai D, Sarker D and Maher J: Prospects for adoptive immunotherapy of pancreatic cancer using chimeric antigen receptor-engineered T-cells. Immunopharm Immunot 38: 50-60, 2016.

96. Parkhurst MR, Yang JC, Langan RC, Dudley ME, Nathan DAN, Feldman SA, Davis JL, Morgan RA, Merino MJ, Sherry RM, et al: $\mathrm{T}$ cells targeting carcinoembryonic antigen can mediate regression of metastatic colorectal cancer but induce severe transient colitis. Mol Ther 19: 620-626, 2011.

97. Kaldor JM, Day NE, Pettersson F, Clarke EA, Pedersen D, Mehnert W, Bell J, Høst H, Prior P, Karjalainen S, et al: Leukemia following chemotherapy for ovarian cancer. N Engl J Med 322: 1-6, 1990 . 